\title{
Motricidad y corporeidad como relaciones basadas en el desarrollo de lo humano
}

\section{Motor skills and corporeality as relationships based on the development of the human}

Napoleón Murcia-Peña (napo2308@gmail.com) Departamento de Estudios Educativos, Universidad de Caldas (Manizales, Colombia) https://orcid.org/0000-0001-9657-2086

Giovanni Corvetto-Castro (gcorvettoc@unmsm.edu.pe) Facultad de Educación, Universidad Nacional Mayor de San Marcos (Lima, Perú) https://orcid.org/0000-0003-3320-0538

\begin{abstract}
The relationships between motor skills and corporeality are fundamental in a consideration of human development. To show the particularities of each one of them, as well as their dimensions, and analyze their strong articulation, it is important for us to understand their humanizing nature. The text shows the differences between motor skills and corporeality and argues from the analogy of magmas the possibility of understanding their overlapping relationship and difference to develop a concept towards the development of the human being.
\end{abstract}

Key words: motor skills, corporeality, human development, creation.

\section{Resumen}

Las relaciones entre motricidad y corporeidad son fundamentales en una consideración de desarrollo humano. Mostrar las particularidades de cada una de ellas, así como de sus dimensiones, y analizar su fuerte articulación, nos resulta importante para comprender la naturaleza humanizadora de las mismas. El texto muestra las diferencias entre la motricidad y la corporeidad y argumenta desde la analogía de los magmas la posibilidad de comprender su imbricada relación y diferencia para poder desarrollar un concepto hacia el desarrollo de lo humano del ser.

Palabras clave: motricidad, corporeidad, desarrollo humano, creación.

\section{Introducción}

Se parte de problematizar la siguiente tesis: el movimiento es el cambio de posición de un órgano o región del cuerpo en relación con el tiempo, desplazamiento mecánico y funcional, alejado de la acción intencionada, pensada cargada de emoción, cuál expresión de lo humano; entre tanto, la motricidad es esa dimensión simbólica e imaginaria del movimiento humano. El cuerpo humano es la estructura somática definida por un complejo biológico/funcional, conformado por aparatos, 
sistemas y órganos. Mientras que la corporeidad, es el cuerpo social y culturalmente configurado, en un proceso continuo de construcción humanizadora, donde la motricidad es el eje. Ambos, corporeidad y motricidad no pueden ser la una sin la otra.

El ser humano no puede ser sin una conciencia socio-histórica y psíquico/somática que se conjugan a la vez para constituirlo; la corporeidad y la motricidad, son justamente esa dimensión de la conciencia psicosomática hecha historia y tradición. En otras palabras, un cuerpo y un movimiento, hechos conciencia socio-histórica y psíquica, esa humanización del cuerpo es la corporeidad y esa humanización del movimiento es la motricidad.

Efectivamente, el cuerpo humano se diferencia de otros cuerpos, fundamentalmente porque es labrado por la historia, la tradición, y la creación radical de la psique/soma, que definen finalmente la corporeidad. Hablar de corporeidad no es hablar de un cuerpo cualquiera; es hablar de un cuerpo atravesado por el sentido de la vida, atravesado por la fuerza de la historia como trasformación y tradición, pero también atravesado por la propia creación del ser humano particular, cada cuerpo con una propia identidad construida a través de las interacciones sociales en respuesta a lo otro, los otros y hacia sí mismos. Es decir, el "cuerpo humano" es la conjugación compleja de la dotación biológica, la construcción social y la creación radical; la esencia de dicha conjugación es la corporeidad. La corporeidad es síntesis de la articulación magmática de cuerpo cargado de herencia, sentido social y creación radical. Como en un magma (que es el componente donde se funden incesantemente diversas sustancias y forman un cuerpo único en el que no es posible separar cada uno de sus componentes), la corporeidad es la síntesis de las herencias biológicas y genéticas, de las fuerzas sociales, pero también de la creación psicosomática.

El cuerpo humano se diferencia de otros cuerpos, fundamentalmente porque es, a la vez, creación y creatura; creatura desde herencias biológicas, exigencias sociales, determinaciones culturales, pero a la vez creatura única e irrepetible, generatividad desde su propia creación psicosomática, que empuja a matizar ese cuerpo desde sus propias determinaciones, desde aquello que lo hace ser un cuerpo particular. Dice Cornelius Castoriadis, para referirse la posibilidad creadora del que tenemos los seres humanos: "Uno de los conceptos claves es la imaginación creadora, cuando el sujeto social interpreta, vive y actúa dentro de la sociedad, lo hace a partir de su visión particular, a partir de lo imaginario efectivo, pero produciendo por su interpretación, un imaginario radical instituyente" (Castoriadis 1983:220).

Incluso ese ser que como corporeidad se mueve en un tiempo y espacio, tiene como particularidad la generatividad, o sea, se diferencia de otros seres que se mueven en un tiempo y espacio por la "potencia de automodificación indeterminada y al propio tiempo indeterminante. Solo así sería posible pensar el tiempo del ser como emergencia de lo nuevo, y la historia de los hombres como su historia verdadera, es decir, un proceso que no está determinado causalmente, sino que es totalmente creador" (Poirier 2004:76).

Así como el ser humano viene dotado de un cuerpo que al hacerse humano se configura como corporeidad, el ser humano viene dotado de un movimiento, una dotación biológica motriz; esta dotación, en la medida de su maduración y desarrollo se va corporizando, o sea la va convirtiendo en motricidad. 
Al igual que la corporeidad, la motricidad es creación y creatura, expresa la fuerza social y cultural, pero a la vez matiza esa expresión desde su propia creación, desde su particularidad. Cuando el movimiento biológico del que venimos dotados se hace intencionalidad, propósito, conciencia de acción, cuando se dota de esa dimensión de humano/social; o sea, cuando se pregna de lo simbólico, se convierte en motricidad.

La motricidad entonces no es mero movimiento; es acción en la vida cotidiana, que implica el movimiento lleno de intencionalidad simbólica. Ahora bien, la dimensión simbólica es la que dota de significado el mundo; significado que es compartido socialmente, pero que puede ser también radicalmente novedoso. Las imágenes que creamos sobre el mundo, por ejemplo, y que inicialmente se consideraban como copias meramente sensibles de la relación del cuerpo con el objeto que la imagen representaba, es problematizada por Ernest Cassirer, quien considera que "ella no expresa en forma meramente pasiva algo presente, sino que encierra una energía del espíritu que es autónoma y a través de la cual, la simple presencia del fenómeno recibe una significación determinada, un contenido ideal peculiar" (Cassirer 1971:18). En Castoridis esta pregnancia simbólica es justamente la base de la creación y modificación constante de los seres humanos y del mundo; de esa creación que es situada por la fuerza de la imaginación y que permite matizar las realidades dadas, organizadas, ensídicas y las realidades racionales. Esta imaginación se canaliza justamente desde los imaginarios radical instituyentes (psicosomáticos) que van generando nuevas determinaciones desde la fuerza social que ellos van logrando. O sea, pese a que existe una cierta organización del ser humano y del mundo, ella permite nuevas organizaciones, nuevas formas de ser/hacer, sentir y representar el mundo. "Creación en el ser, en lo que es, surgen otras formas, se establecen nuevas determinaciones. Lo que cada vez es, no está plenamente determinado, es decir, no lo está hasta el punto de excluir el surgimiento de otras determinaciones" (Castoriadis 1996:12).

Entonces, cuando hacemos del movimiento una acción de vida, estamos hablando de la dimensión simbólica, imaginaria de ese movimiento humano, estamos dotando de humanidad ese movimiento de dotación biológica. De no ser por la dimensión simbólica que asignamos al mundo, tendríamos los mismos comportamientos que los animales, con los cuales compartimos la mayoría de los sistemas corporales y motores. De hecho, ni siquiera el mundo sensible lo compartimos de la misma forma con los animales, pues nuestro sentido simbólico cruza nuestra sensibilidad. En últimas, sentimos el mundo con nuestra corporeidad y actuamos frente a este con nuestra motricidad. "Por eso, solo en la función simbólica se encuentra la posibilidad de comprensión de una realidad compleja" (Cassirer 1971:57) de la relación motricidad/corporeidad.

Pero esto solo es posible en el marco de una compleja relación asimilada como una articularidad magmática. Esta perspectiva, desarrollada por Cornelius Castoriadis en sus múltiples obras para mostrar la imbricada relación que hay entre las dimensiones del ser humano, será la base de argumentación en este texto para mostrar que no es lo mismo hablar de cuerpo, motriz, motricidad, corporeidad, humanidad, cultura, sociedad, simbólico, en tanto cada una de estas guarda sus particularidades. Pero ellas se funden en esa substancia que configuran la humanidad del ser humano. Un ser humano, lo es, en tanto sujeto de corporeidad/motricidad y estas dimensiones solo se configuran desde las relaciones con lo simbólico, la herencia cultural y social, tal y como se verá más adelante.

En una referencia sobre la naturaleza magmática del lenguaje, Castoriadis muestra esta profunda relación: "La dimensión identitario conjuntista, en y por la cual el lenguaje es código, es imposible 
(sin e indisociable de) su dimensión significativa, en y por la cual el lenguaje existe en tanto lengua; de la misma manera el teukhein en tanto identitario-conjuntista es inseparable de la dimensión imaginaria de hacer, y del magma de significaciones sociales a que el hacer social da existencia" (Castoriadis 1989:165).

La capacidad del lenguaje para establecer comunicación solo es posible porque existe un sistema de signos que están definidos, pero que solo significan en el escenario de la intencionalidad humana. La capacidad de creación está justamente en la posibilidad exclusiva que tienen los seres humanos para matizar el signo, o para reconocer los matices dados por otros grupos o seres humanos. Lo anterior, por cuanto esa capacidad de significar depende de las impresiones sociales, pero también de la capacidad particular, definida por la psiquesoma.

Porque los seres humanos construimos "el modo de ser para sí" (Castoriadis 1996:24) que es esa tipicidad que, incluso los animales, le damos a lo establecido en el mundo para poder vivir, para adaptarnos a él. Mientras la tipicidad en los animales está fundamentada en las dotes genéticas de la supervivencia, en los seres humanos está mediada, además, por las significaciones sociales y estas significaciones son originadas por la creación conjunta de lo social, pero también por la creación particular de lo psicosomático. Esta capacidad así es asumida en El ser en Castoriadis de Nicolas Poirtier cuando define ese ser psíquico que implica la aparición de una imaginación abierta y desfuncionalizada. En sus palabras, esto constituye una primera ruptura del ser para sí, en cuanto define un tipo de ser particular: el ser humano.

El ser humano, entonces, no puede serlo fuera de esa relación magmática entre el soma y la psique. El soma como la organización ensídica del mundo que compartimos con los animales y la psique como esa dimensión que permite la significación imaginaria. Catoriadis lo plantearía de esta forma en Hecho y por hacer cuando asume que la fuente de la creación del ser humano es la imaginación definida desde esa substancia que se configura al fundirse la fuerza biológica del soma con la fuerza creadora de la psique, en la entidad que llama psiquesoma. Sin embargo, pese a esta imbricada relación, Castoriadis reconoce el carácter no funcional del psiquismo humano, que no está sujeto a regulaciones funcionales del instinto animal y por tanto portadora de una imaginación radical, desfuncionalizada, capaz de crear y no simplemente de repetir o imitar.

Esta entidad se configura también en una relación magmática con lo social, en tanto tradición e historia, pero también creación. Esto significa que no es posible un ser humano sin la fuerza de esas significaciones altamente instituidas, hegemónicas, sancionadas por lo social, pues desde ellas se definen las dinámicas funcionales de las instituciones y sociedades, desde ellas organizamos nuestras acciones e interacciones en el mundo. Pero tampoco es posible un ser humano sin la fuerza creadora de ese colectivo anónimo y su relación con las particularidades de los sujetos. Pues, si bien, el ser humano crea matices a esas dimensiones organizacionales, el colectivo crea también cada vez formas de organización social que permiten a los seres humanos vivir de unas formas determinadas. "No podemos pensar ese imaginario social que crea el lenguaje, que crea las instituciones, que crea la forma misma de la institución -la cual no tiene sentido sin la perspectiva misma de la psiquis singular- sino como capacidad creadora del colectivo anónimo que surge toda vez que los seres humanos se reúnen y que en cada oportunidad adopta una figura singular, instituida, para existir" (Castoridis 1998:113). 
Así, motricidad y corporeidad son dimensiones que guardan sus particularidades, pero que se funden en esa substancia que configura la dimensión corpóreo/motricia del ser humano. Lo corpóreo que se configura desde el cuerpo creado y lo motricio descifrado desde eso que le agregamos al movimiento de que venimos dotados naturalmente. Motricidad y corporeidad ayudan a configurar la humanidad del ser humano como un todo indisoluble. En síntesis, la motricidad es la humanización del movimiento y la corporeidad es la humanización del cuerpo; pero la humanización del ser humano no es posible sin esta conjución magmática, tal y como se desarrollará más adelante.

\section{Trasgresión de la dimensión biológica del cuerpo}

Es indudable que el cuerpo representa esa dimensión biológica de que estamos dotados los seres en el mundo. Esa dimensión material, que compartimos con los otros seres y objetos que habitamos el universo, en cualquiera de sus niveles. Se refiere a la dimensión evidente que nos presenta como cuerpos que ocupamos un lugar en el espacio. En los seres vivos corresponde a esa dimensión biológica que permite y hace posible la funcionalidad de lo viviente.

No puede desconocerse que el cuerpo es nuestro componente somático que contiene sistemas, sin los cuales sería imposible la vida, sin importar si en ella opera o no la intencionalidad; sin importar si ese cuerpo corresponde a un nivel preantrópico (viviente pero sin referencia cultural) o a un nivel antrópico (pregnado por la cultura). Por esto y pese a las diferencias y similitudes, compartimos un cuerpo animado con todo lo que tiene existencia viva.

Es evidente también, que los cuerpos que pertenecen al nivel abiótico, a ese nivel sin vida del universo, deben ser problematizados desde las ciencias abióticas; entre tanto, aquellos que pertenecen al nivel biótico, deberían ser analizados, estudiados desde las ciencias bióticas, pero teniendo en cuenta el sub-nivel en el cual se ubican, como seres vivos no intencionados (nivel preantrópico); o como seres vivos intencionados y definidos culturalmente, esto es como seres simbólicos (nivel antrópico).

Pero la complejidad de lo humano hace de esta problematización un asunto de mayor envergadura, pues el nivel antrópico del cuerpo se conjuga con el nivel pre-antrópico, en tanto en su perspectiva funcional se comparten similares sistemas. O sea, cuando hablamos del cuerpo humano estamos hablando de un cuerpo que vive y por tanto es correspondiente con los otros cuerpos que viven; su existencia es como soma (corpóreo, material); pero el cuerpo humano vive como soma y a la vez como psique; esto es, un cuerpo que, pese a que tiene una dimensión funcional, no puede verse por fuera de su dimensión simbólica; compartimos la mayoría de los sistemas con los cuerpos de otros seres vivos; compartimos también las mismas cosas del mundo externo, pero no de la misma forma; justamente eso que nos hace diferentes en la forma de compartir el mundo, es la capacidad de significarlo, la capacidad de dotarlo de sentido de acuerdo a nuestra necesidad e intencionalidad.

Merleau Ponty deja clara la intencionalidad de mostrar el cuerpo desde su racionalidad fenomenológica como situado en el mundo de la vida. Se opone a toda perspectiva que cosifique el cuerpo humano y a cualquier reduccionismo de su complejidad; desde su postura se genera una potente crítica al dualismo cartesiano por considerar que, en este, el cuerpo humano es substancia - cosa fraccionada, substancia extensa y substancia pensante, según Descartes, y asume la irreductibilidad de su configuración como totalidad. Es la unidad significante dotada de sentido, en la cual la corporeidad es el modo de ser en el mundo. El ser humano es conciencia y cuerpo a la vez, 
y por tanto no hay un para sí y un en sí, tal y como lo propondría Sartre, pues esto implicaría que tengo un cuerpo y que este puede ser usado por mi psique. En su consideración, soy un cuerpo en el mundo y, por tanto, el mundo es configurado por mi humanidad y esa humanidad es todo lo que soy; con mi historia, tradición y herencia biológica. "Hay un hombre efectivo, real, concreto, que no se limita a poseer conciencia o cuerpo o a enfrentarse con la realidad externa, sino que es conciencia y cuerpo (o conciencia-cuerpo)" (Ponty 2000:57).

La fuerza social, esos determinantes de organización histórica, que agitan la creación de los colectivos, es también fuente de configuración de esa corporeidad que a su lado se transforma para decir algo de las culturas. David Lebreton hace este análisis desde su racionalidad antropológica, pese a lo cual asume la función simbólica en la determinación y subjetivación del cuerpo humano: "Las representaciones sociales le asignan al cuerpo una posición determinada dentro del simbolismo general de la sociedad. Sirven para nombrar las diferentes partes que lo componen, y las funciones que cumplen, hacen explícitas sus relaciones, penetran en el interior invisible del cuerpo para depositar allí imágenes precisas, le otorgan una ubicación en el cosmos y en la ecología de la comunidad humana" (Lebreton 1990:13).

En los análisis que el autor hace sobre el cuerpo asume una profunda relación simbólica con lo social: "las representaciones del cuerpo y los saberes a cerca del cuerpo son tributarios del estado social, de una visión del mundo y, dentro de esta última de una definición de la persona" (Lebreton 1990:13). Entonces, el cuerpo hecho conciencia, intencionalidad, dotado de esa dimensión simbólica, ya no es cualquier cuerpo, es un cuerpo humano al que llamaremos corporeidad. Esa dimensión simbólica del cuerpo es recreada por Rubiela Arboleda en sus múltiples estudios, uno de los cuales es documentado por Sandra Pedraza quien advierte: "La autora no se limita a reconocer el cuerpo y la corporeidad como productos culturales; ante todo, considera que en el cuerpo se exponen ciertas dimensiones de la cultura, encarnadas de manera tal que sirven para reconocer diversos fenómenos sociales" (Pedraza 2010:341).

La naturaleza fenomenológica de la corporeidad, en tanto condición de presencia, participación y significación en el mundo, es analizada por Margarita Benjumea, quien considera que: "el ser humano posee un cuerpo, pero no es un cuerpo exclusivamente objetual, es un cuerpo que vive, que es expresión. El Humanes ya no solo 'posee' un cuerpo que solo hace, sino que su existencia es corporeidad, corporeidad que implica hablar de su integralidad y no de una parte del ser" (Benjumea 2003:7). Para Corvetto: "La corporeidad determina el vínculo de mi ser en sintonía con mi ser corpóreo en el mundo, el goce, las emociones, la autonomía, el autoconcepto la imagen que representamos y la imagen de los otros hacia nosotros, significados imaginarios de la vida cotidiana que se van modificando a lo largo de nuestras vidas, en diferentes etapas hasta el final de nuestros días" (Corvetto 2018:141).

Justamente, Deibar René Hurtado ha buscado esta fuerza creadora en los movimientos sociales juveniles inicialmente desde las modificaciones corporales que definen una manera clara de expresión de la naturaleza "ser humanos" de este grupo poblacional. En sus estudios el autor deja ver que además de una forma de revelarse en contra de lo establecido, las modificaciones y los movimientos sociales juveniles son formas sensibles de buscar la libertad, disfrute y solidaridad: "Son prácticas culturales, pero del mismo modo espacios de libertad y diversión que tienen como finalidad el gozo, y que podrían ser considerados como prácticas de individualización. Sin embargo, es necesario resaltar la importancia de matizar esta afirmación, ya que junto a estas búsquedas van 
aunados sentimientos de solidaridad para con otros que, como ellos y ellas, precisan de ayuda" (Hurtado 2011:224).

La corporeidad es el encuentro con lo sensible de ser humano, que traspasa el mero contacto, hacia el sentimiento. Es la presencia del mundo en el ser humano que pre-siente, proyecta y realiza en ese sentimiento su intencionalidad. Este análisis expuesto desde la racionalidad pedagógica es analizado por Luz Elena Gallo, quien expone que "hay una nueva modalidad de la experiencia educativa que intenta poner el acento en el cuerpo $y$, en sus variaciones sensibles, rescata la imaginación, la contemplación, la atención, el sentimiento, la percepción, el asombro; así como los principios de introspección, delicadeza, inexactitud, fineza y variabilidad" (Gallo 2014:199).

En las anteriores perspectivas, es evidente que la corporeidad, es construcción simbólica, puesto que deviene de las influencias socio-culturales e intencionadas del ser humano, que lo fuerza a ser lo que se quiere llegar a ser como corporeidad; una corporeidad orientada al rendimiento, una orientada a la belleza, una orientada al trabajo y así.

Mientras que el cuerpo es la organización natural de la vida, es esa dimensión ensídica que está definida desde las herencias y dotaciones biológicas, por tanto, es la corporeidad que es imposible sin ese "ser cuerpo" se proyecta como posibilidad, se configura en la historia, la tradición y la fuerza psicosomática del imaginario radical. Bien lo dirían Jhon Fredy Orrego y Diego Jaramillo: "El cuerpo es, mientras que la corporeidad llega a ser y, a la vez, llega a ser otra de lo que es, llega a ser distinta, llega a ser contra lo que es... y, también, nunca es del todo, porque un ser corpóreo remite a un escenario abierto, siempre móvil, un escenario que no puede eludir el pasado, el recuerdo de lo que ha sido, de lo que le han hecho, la herencia recibida, la gramática en la que ha sido educado y, al mismo tiempo, remite a un porvenir, no solamente a un futuro más o menos previsible, programable o planificable, sino a un porvenir que siempre está por venir, que siempre está abierto a los acontecimientos que rompen cualquier proyecto, cualquier identidad, cualquier fijación" (Orrego y Jaramillo 2019:94).

Porque las relaciones que establecemos los seres humanos con el mundo son posibles gracias a esa carga simbólica que logramos incorporar desde la vida social, gracias a esos acuerdos regulados por lo social que van generando unas significaciones frente a nosotros mismos, a los otros seres humanos y al mundo; y estas significaciones son también sobre nuestro cuerpo y las relaciones con el Otro y lo otro. En síntesis, el cuerpo es mucho más que soma, pues en él se encarna la historia de vida de los seres humanos, las huellas de la historia, la tradición y la creación que se hacen y devienen de experiencia e imaginación y que se configuran como existencia real en la corporeidad. Muchas de esas experiencias son efectivamente motricias $y$, aunque no constituyen la totalidad de la corporeidad, hacen parte de la adaptabilidad, del cuerpo a propósitos específicamente intencionados: a propósitos humanos. Lo motricio se utiliza en el texto para referirse a la expresión básica de la motricidad: que se mueve con un propósito o intencionalidad; re-configurando esta unidad que es utilizada en la racionalidad funcional como motriz; toda vez que motriz refiere esa unidad mecánica de desplazamiento en tiempo espacio.

\section{La intencionalidad de la motricidad}

De la misma forma en que Ponty problematiza en el cuerpo humano, la corporeidad como condición de humanidad del cuerpo, es posible problematizar la motricidad como condición de humanidad del 
movimiento humano: hay un hombre/mujer de carne y hueso que no se limita a poseer conciencia, cuerpo y movimiento, sino que es, a la vez, conciencia, cuerpo y movimiento.

Al igual que la corporeidad ha sido asemejada al concepto de cuerpo, en la tradición fisicalista la motricidad ha sido asemejada al concepto de movimiento. En un estudio realizado por Margarita Benjumea y otros (Develando los Sentidos de la Motricidad en Colombia), se muestra cómo este concepto definido desde la visión dualista del ser humano es aún dominante en las percepciones y prácticas de la educación física en Colombia, en una relación con el concepto de desplazamiento de un cuerpo en el espacio. Quizá relacionado con esta perspectiva, no hemos logrado deslindar el cuerpo de la motricidad, pues son muy frecuentes los estudios que refieren la motricidad como corporeidad, e incluso el cuerpo y el movimiento como una misma cosa. La fuerza de la tradición que empuja a asumir que todo cuerpo que se mueve está realizando una acción motriz, un desplazamiento en el espacio. Pese a la relación evidente con el movimiento y el cuerpo, es importante establecer algunas relaciones que ayuden a definir sus proximidades y diferencias.

Al hacer parte de su naturaleza, la motricidad es constitutiva de "ser humano", pero el ser humano tanto psicosomático como social, constituye también la motricidad. Lebreton afirma con enfática profundidad que "existir significa, en primer lugar moverse en un espacio y en un tiempo [...] a través de su corporeidad, el hombre hace que el mundo sea la medida de su experiencia" (Lebreton 2008:8). Agregaríamos que también es la conciencia motricia como posibilidad de imaginación del ser humano la que hace que el hombre haga el mundo a su medida. $O$ sea, que no es que el mundo sea a la medida de la conciencia, pero tampoco es que el mundo se construye exclusivamente desde la experiencia, pues como lo propone Castoriadis, muchas ideas, generan experiencias.

Venimos al mundo dotados de un movimiento biológico y funcional que permite al cuerpo desarrollar sus funciones básicas de supervivencia y adaptabilidad. Los organismos vivos poseen como base organizacional el movimiento, por eso lo compartimos con estos; movimientos que hacen posible que el organismo como cuerpo funcione, pero también movimientos adaptativos que de forma autónoma y por definición genética permite que estos cuerpos se desarrollen y adapten al medio.

Los seres humanos compartimos estos movimientos con otros seres bióticos; incluso, muchos de ellos tienen mejor posibilidad de adaptación al medio que los seres humanos. Las aves vuelan, los peces nadan muchísimo mejor que el ser humano, las liebres se mueven con mucha más agilidad que los seres humanos... La mayoría mediados por los procesos de maduración y desarrollo, pero muchos animales aprenden nuevas formas de moverse. Entonces ¿qué es lo que hace diferente el movimiento humano del movimiento animal? Muchos teóricos hoy asumen con firmeza y suficiencia científica que los seres humanos configuramos nuestras vidas inmersas en tres dimensiones: la dimensión ensídica, la dimensión racional y la dimensión simbólica/imaginaria. Pese a que es imposible la una sin las otras, la dimensión sobre la cual construimos la vida humana y social es la dimensión simbólica/imaginaria. Cassirer por ejemplo asume que el ser humano lo es gracias a esta dimensión, por tanto, es un animal simbólico. La imbricada relación ha sido figurada de diferentes formas. Lacan lo hizo desde la figura del nudo de Borromeo para establecer la relación entre lo simbólico, lo imaginario y la realidad. Es la forma de convergencia de "esos tres registros que son precisamente los registros esenciales de la realidad humana, registros muy distintos y que se llaman: lo simbólico, lo imaginario y lo real" (Lacan 1953:42). 
Entre tanto, Castoriadis, argumentó su teoría desde la figura de los Magmas, mostrando la relación y diferencias entre la dimensión ensídica, racional e imaginaria. El autor muestra a lo largo de su obra esta relación en cada uno de los componentes de la configuración de imaginarios e instituciones sociales, por ejemplo, en la ontología de la creación, al referirse a la reflexión como ruptura afianza la relación entre lo dado y lo novedoso que se funde para definir nuevas clausuras, desde esa fusión magmática de lo dado socialmente y lo creado por el colectivo anónimo: "La reflexión es definible como el esfuerzo por romper la clausura en la que estamos cada vez, necesariamente tomados como sujetos, clausura que viene de nuestra historia personal o de la institución social-histórica que nos ha formado, a saber, humanizado. En este esfuerzo la imaginación juega un rol central, puesto que la puesta en cuestión de las 'verdades establecidas' no es ni puede ser nunca un cuestionamiento en el vacío, sino que está siempre acompañado con la posición de nuevas formas/figuras de lo pensable, creadas por la imaginación radical y sujetas al control de la reflexión" (Castoriadis 1997:211).

En casos citados, se muestra la imposibilidad de digresión entre las dimensiones de la vida humana, pero además la impertinencia de su unificación. Hemos afirmado que en el movimiento compartimos esa dimensión ensídica, o sea esa dotación biológico-funcional, pero los únicos que dotamos de intención, propósito, sentido, significado el movimiento del que venimos dotados somos los seres humanos. Somos los únicos que nos movemos no solo con el propósito funcional que el sistema biótico nos implica, no solo con el propósito adaptativo que la naturaleza nos impone, sino que lo hacemos por que queremos. Porque dentro de nosotros existe un propósito que es superior al del mando genético, el propósito simbólico; dotamos el movimiento de esa dimensión simbólica que además de ser particularmente única, nos conmina como exigencia social a ser general.

Nos movemos porque queremos hacer con ese movimiento algo, que significa, algo que nos proyecta, que nos llena de emoción o simplemente no nos movemos porque eso también significa, proyecta, conmueve. Nos movemos porque nos toca (es una justificación que define intencionalidad), porque quiero mejorar mi salud, porque quiero practicar algún deporte, porque quiero llegar a ser algo. La particularidad del "ser humanos" es, justamente ser inacabados, ser en proyecto, y quienes definimos esa ruta somos nosotros mismos. Su definición está influida por muchas cosas, lo genético, lo social y lo psicosomático; todas ellas se funden como un magma, para proyectar lo que queremos y podemos llegar a ser. Franco Yogo considera que "Castoriadis llama magma, a un modo de coexistencia en fragmentos de múltiples organizaciones lógicas pero no reductible a una organización lógica. La noción de magma es aplicada tanto a la psique en tanto expresión de la imaginación radical, como a la sociedad en tanto magma de significaciones sociales" (Yogo 2003:11).

Es claro entonces que no solo nos movemos, sino que podemos proyectar el cómo queremos movernos. La base de esta proyección es la fusión de las herencias biológicas, las tradiciones sociales/culturales, pero también la fuerza de la psique/soma que quiere lograr una forma de moverse y por tanto matiza y fuerza esa dotación y fuerza socio-cultural a su forma particular de movimiento, su estilo motricio. Por supuesto que la motricidad no puede ser sin el movimiento del que venimos dotados, de hecho, por eso, en esta racionalidad, no es posible hablar de discapacidad por venir menos dotado motrizmente que otro ser humano, pues este epíteto correspondería a aquella persona que no es capaz de corporeizar esa dotación biológica motriz. Se discapacita solo 
aquel que no potencia su capacidad biológica, sea cual fuere, hacia la humanización, esto es, hacia la corporeidad y motricidad.

El concepto de perfeccionamiento de un movimiento no es otra cosa que corporizar de la mejor manera ese movimiento de dotación, y dicha corporización siempre tiene un propósito que necesariamente es simbólico, pues significa para quien lo define, bien como imaginario social o imaginario radical. Así, un buen deportista es quien es capaz de corporizar, de tal forma los gestos técnicos del deporte, que los hace suyos; los hace tan únicos que definen su personalidad motricia.

El perfeccionar el movimiento le permite al ser humano generar una forma particular de moverse; una especie de estilo motricio, que sería la corporación ideal del movimiento, la realización más humana de la motricidad, pues implica hacer mío ese movimiento del que estoy dotado. Hacerlo mío el movimiento, es darle a ese movimiento mi personalidad, dotarlo de mi propio sello; esto es, significarlo para interiorizarlo como parte de mi corporeidad. Ese estilo, se define desde la proyección de lo que quiero y puedo llegar a ser.

O sea, no se nace con un estilo motricio, se llega a ese estilo desde la apropiación, corporización del movimiento del que se está dotado. Como se ha expresado, no nacemos siendo humano, sino que llegamos a serlo y para esto luchamos toda la vida despojando o minimizando eso que nos aleja de ser humanos. Por eso, lograr el estilo motricio es trabajo de toda la vida, e implica proyección, esfuerzo y voluntad. Es una especie de tránsito humano que lleva a los seres a habitar su cuerpo: “Habitar el cuerpo es vivir en diálogo con el mundo. Él no reacciona a un estímulo causal del cual se pueden extraer fórmulas y leyes físicas para justificar un experimento; si hay cuerpo es porque éste dice algo al mundo. Dialoga con este último, correlato constituyente que abriga toda descripción vital" (López y Jaramillo 2018:88).

Ese diálogo no es solamente para adaptarnos al mundo (pues esa adaptación puede ser meramente funcional), sino para construir el proyecto de vida hacia el cual orientaremos las acciones e interacciones de todo mi ser, hacia la configuración de ese ser humano que pretendo ser. Por supuesto que existe una relación simbiótica entre el contacto con el mundo a través de la motricidad como acción del sujeto intencionada y la construcción del ser corpóreo, el mismo que se conjuga a través de la percepción que es innata, la misma que no solo percibe calor, frio, hambre, sino emociones, expresa emociones, dolor, belleza, tristeza, amor, disgusto, decepción, alegría, motricidad, que es propia de cada ser humano y determina su esencia, por tanto no iguala a la de ningún otro ser en el mundo.

\section{Aperturas para pensar algunas conclusiones}

La gran mayoría de los procesos y prácticas sociales de la vida cotidiana requieren la complacencia de ese entramado complejo de la motricidad y la corporeidad, ese entramado que en muchas ocasiones es definido por la fuerza de lo social, pero que es matizado por la aspiración y necesidad radical de la creación del ser humano, eso que empuja a que los seres humanos no solo seamos sujetos somáticos dotados genética y biológicamente, sino que soportemos la constante idea de ir más allá de lo establecido. La motricidad es esa dimensión simbólica del movimiento, permite llegar a ser más humanos en tanto proyectamos desde la corporación lo más profundo de nuestro ser, la proyección hacia el otro. 
Algunas consideraciones podrían ser tomadas en cuenta a partir de los análisis. La motricidad no es la expresión corporal, pues no es la respuesta instrumental o funcional del cuerpo, no está al servicio del cuerpo; tampoco es el resultado del ordenamiento psicológico, en tanto no depende exclusivamente de las órdenes definidas en la psique (psicomotricidad); no es el resultado absoluto de las exigencias o imperativos socioculturales, ni sigue los mismos patrones del lenguaje (praxeología motriz). Su manifestación no es una mera "expresión corporal", es la expresión de un sentimiento de humanidad particular, de un sentimiento que cada ser ha ido forjando con su intención, proyección y experiencia. Es una dimensión de la humanidad del ser humano que tiene sus propias epistemes y principios y por tanto no sigue las racionalidades de lenguaje. "Mediante una práctica corporal, el cuerpo practica formas de experiencia, porque con el movimiento corporal se expresan modos de ser de la persona, y la percepción que la persona tiene de ellos puede generar una determinada experiencia" (Gallo 2012:826).

Acaso la motricidad es como "las prácticas corporales que podemos entender como esas acciones o fuerzas que actúan sobre el cuerpo [y que actúan] como formas de expresión de lo sensible" (Gallo 2014:202). Posiblemente la práctica corporal es una práctica social en la lógica de esta como "expresión de humanidad" tal y como lo propone Murcia, Jaime y Gómez: "Reconocer la práctica social es reconocer el ser humano que la desarrolla, pues en ella se esboza la fuerza de las significaciones imaginarias sociales que hacen generar representaciones en el marco de las cuales se definen las acciones e interacciones humanas; por tanto, una práctica social no puede reducirse a una actividad, pues ella no es más que el producto realizativo de un cúmulo de convicciones / motivaciones y creencias fuerza que la orientan. No implica que esas convicciones / motivaciones y creencias sean meras fuerzas sociales que desde afuera inducen al sujeto a actuar de una $u$ otra forma, pues, ellas sicosomáticas que configuran dichas manifestaciones" (Murcia, Jaimes y Gómez 2016:272). La conexión con esta propuesta se podría encontrar en las continuas referencias que la autora realiza respecto de las prácticas corporales como expresión de humanidad, como divulgación de ese sentimiento humano mediado por la corporación del movimiento: "Podríamos decir que las prácticas corporales se corresponden con un performance corporal, potencia de creación, flujo de relaciones que nos exponen a procesos de (trans) formación" (Gallo 2012:827).

Otro aspecto es que, en la medida que el movimiento del que venimos dotados se funde como intencionalidad a nuestro proyecto de ser humano, se corporiza y permite el estilo motricio. Todas esas expresiones que se manifiestan mediadas por el cuerpo/motricidad, son en realidad expresiones de eso que le agregamos al mundo, de eso que aportamos como seres humanos al movimiento y al cuerpo. No es la capacidad motriz la que define la humanización, sino la fusión entre esta, el deseo y la proyección. Por eso no puede haber discapacitados, sino seres humanos que no proyectamos nuestra motricidad en la configuración de nuestra humanidad. Efectivamente, nacemos dotados de un cuerpo, cuerpo que puede tener todos los órganos y sistemas, pero también podríamos nacer dotados de un cuerpo que no los posee o que, poseyéndolos, no tienen la posibilidad de ser operados funcionalmente según la dotación biológica, ni se proyectan en el marco de esta posibilidad.

En este caso, la capacidad humana de adaptar esa falencia a las necesidades de los contextos intencionados es justamente una de las posibilidades de humanizar ese cuerpo y esto lo hacemos en gran parte desde la motricidad. En cada momento de la vida, desde la gestación hasta la muerte, estamos humanizando el cuerpo, estamos llenándolo de vida humana para hacer de este una real corporeidad/motricidad, de tal forma que, pese a que nacemos siendo cuerpo somático y 
movimiento, no nacemos siendo corporeidad ni motricidad, sino que llegamos a serlo. Esto por cuanto la motricidad es, además de lo común, creación, indeterminación. Siendo que la motricidad y la corporeidad no pueden existir la una sin la otra, pero tampoco la capacidad psico/somática, la fusión de estas permite corporizar el movimiento genéticamente dado para proyectarlo a nuestra configuración humana como proyección y constante creación. Esto es, no nos movemos sin el cuerpo, pero tampoco podemos tener corporeidad sin motricidad y sin intencionalidad.

\section{Bibliografía.}

Cassirer, E. 1971. Filosofía de las formas simbólicas. Fondo de cultura económica.

Castoriadis, C. 1998. El ascenso de la insignificancia. Cátedra.

Castoriadis, C. 1997. Ontología de la creación. Ensayo y error.

Castoriadis, C. 1996. Hecho y por hacer. Pensar la imaginación. Eudeba.

Castoriadis, C. 1989. La institución imaginaria de la sociedad, vol. 2. TusQuest.

Castoriadis, C. 1983. La institución imaginaria de la sociedad, vol. 1. TusQuets.

Corvetto, G. 2018. Evolución histórica de la educación física en el currículo escolar peruano. Un análisis sobre los enfoques y el que hacer pedagógico en el área. ALESDE, 9(2), 134-153. https://revistas.ufpr.br/alesde/article/view/61274

Gallo, L.E. 2012. Las prácticas corporales en el horizonte de la educación corporal. Revista Brasileira de Ciências do Esporte, 34(4), 825-843. https://doi.org/10.1590/S0101$\underline{32892012000400003}$

Gallo, L.E. 2014. Expresiones de lo sensible: lecturas en clave pedagógica. Educação e Pesquisa, 40(1), 197-214. https://doi.org/10.1590/S1517-97022013005000027

Hurtado, D.R. 2011. Ciudadespacios. Recorridos y tránsitos de las prácticas culturales de jóvenes por la ciudad de Popayán. Revista Latinoamericana de Ciencias Sociales, Niñez y Juventud, 9(1), 215-226. http://revistaumanizales.cinde.org.co/rlcsnj/index.php/RevistaLatinoamericana/article/view/353

Lacan, J. 1953. Lo simbólico, lo imaginario y lo real. Biblioteca E.F.B.A.

Lebreton, D. 1990. Antropología del cuerpo y modernidad. Edición nueva visión.

Lebreton, D. 2008. Sociología del cuerpo. Edición nueva visión.

López, R; Jaramillo, L.G. 2018. Cuerpo se escribe con p: presencia, palabra y pensamiento en la escuela rural de hoy. Nómadas, 49, 88-101. https://doi.org/10.30578/nomadas.n49a5

Murcia, N; Jaimes, S; Gómez, J. 2016. La práctica social como expresión de humanidad. Cinta de Moebio, 57, 257-274. https://doi.org/10.4067/S0717-554X2016000300002

Orrego, J.F; Jaramillo, D.A. 2019. Educación, cuerpo y alteridad. Encuentros cara a cara para la formación del otro. Alteridad revista de educación, 14(1), 89-97. https://doi.org/10.17163/alt.v14n1.2019.07

Pedraza, Z. 2010. Reseña de El cuerpo: huellas del desplazamiento de Rubiela Arboleda. Tabula Rasa, 12, 341-345. 
Poirier, N. 2004. Castoriadis. El imaginario radical. Ediciones nueva visión.

Ponty, M. 2000. Fenomenología de la percepción. Ediciones Península.

Yogo, F. 2003. Cornelius Castoriadis. Psicoanálisis, filosofía, política. Eudeba.

Recibido el 23 Jul 2020

Aceptado el 15 Dic 2020 